\title{
Accuracy of Fibrinogen/D-dimer Ratio in Predicting the Occurrence of Coronary Slow Flow Phenomenon
}

\author{
Taufik Indrajaya ${ }^{1 *}$, Alie Ghanie ${ }^{1}$, Andi Arman ${ }^{1}$ \\ ${ }^{1}$ Department of Internal Medicine, Division Cardiovascular, Faculty of Medicine, Universitas Sriwijaya, Palembang, Indonesia
}

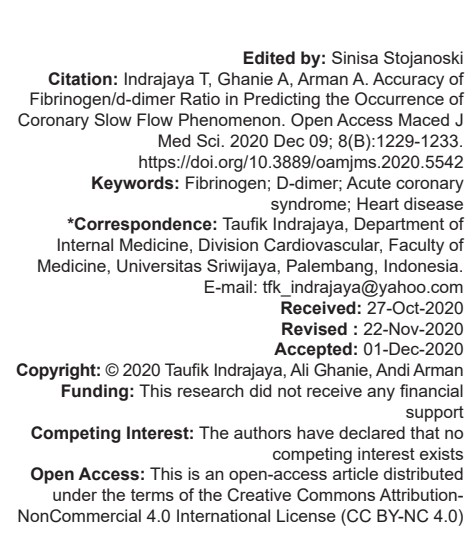

Introduction

Coronary slow flow phenomenon (CSFP) is the presence of slow flow in one or more coronary artery branching vessels that are seen during contrast angiographic actions. There are differences in defining CSFP; it has been reported that the range of events is $1-7 \%$ in the angiographic series and up to $5 \%$ in cases of an acute coronary syndrome (ACS) [1], [2]. There are two methods of measuring the slow flow phenomenon [2]. The first method is thrombolysis in myocardial infarction (TIMI) flow grade from contrast scores ranging from TIMI 0 (no flow), TIMI 1 (penetration without perfusion), TIMI 2 (flow, including delayed filling), and TIMI 3 (normal flow, opacification of distal vessels in $<3 \mathrm{~s}$ ). The second method is the corrected TIMI frame count, which is the number of frames needed by contrast material to reach a specific distal coronary artery point with a standard range of 21 \pm 3.5 [1], [3].

Patients generally experience recurrent chest pain, which occurs in resting conditions (80\%), and around $20 \%$ require emergency treatment. This condition may cause arrhythmia and sudden cardiac death. CSFP is considered to be an early phase of atherosclerosis involving both small arteries and epicardial arteries, so that management is essential to prevent heart failure in patients [2], [3]. The endothelium plays a critical role in the regulation of vascular pressure, platelet activity, smooth muscle proliferation vascular, and plays a role in the initiation of the formation of atherosclerosis. Therefore, endothelium dysfunction is believed to be one of the causes of CSFP coronary artery heart conditions [4].

Fibrinogen is an essential component in the coagulation cascade and affects hemostasis, hemorheology, platelet aggregation, and endothelial function [5], [6]. In the other hand, D-dimers are inevitable products of fibrin degradation that results from thrombin activation; XIII activated factors and plasmin. The presence of $\mathrm{D}$-dimer in plasma is an indication of thrombus formation. Measurement of D-dimers, markers of thrombosis and hypercoagulation, the value of $D$-dimers can be associated with the amount of fibrin formation [7], [8]. Fibrinogen and D-dimers are believed to play a role in the pathogenesis of coronary heart disease (CHD), namely atherogenesis, platelet aggregation, and platelet formation [5], [6]. 
However, not all countries or health services have highly developed angiography facilities and services; some other methods of measuring and coordinating the coronary blood flow are needed. This study is expected to analyze the accuracy of the fibrinogen/D-dimer ratio as a predictor for CSFP in patients with heart disease.

\section{Methods}

The study design is a diagnostic test with a cross-sectional design to assess the accuracy of the fibrinogen/d-dimer ratio in predicting CSFP in CHD. The study was conducted at Catheterization Laboratory in Dr. Moh Hoesin Hospital, Palembang, Indonesia. Submission of subjects was conducted from March 1, 2020, to March 30,2020 . The ethics committee approved this study of the Faculty of Medicine of Universitas Sriwijaya with registration number 188/kptfkunsri-rsmh/2020.

The subjects were 45 patients who underwent diagnostic and therapeutic measures in Dr. Moh Hoesin Hospital, Palembang, Indonesia, which meet the inclusion and exclusion criteria. The inclusion criteria are all patients with CHD who has diagnosed by a cardiologist; the patient has ECG changes such as ST-elevation or depression, patient aged between 30 and 80 years old and willing to participate in research and signed informed consent. Exclusion criteria were patients with chronic kidney disease and hepatitis, patients with malignant diseases, patients with infectious diseases, experiencing acute myocardial infarction attacks, pregnant and breastfeeding, currently using anticoagulant drugs.

The independent variables in this study were serum fibrinogen and D-dimer levels. Meanwhile, the dependent variable is sufferers of CHD with CSFP and regular flow. The confounding factors in this study are gender, obesity, smoking history, diabetes mellitus, hypertension, and dyslipidemia.

All data obtained from this study were analyzed using the SPSS version 20.0 for Windows program with a $95 \%$ confidence limit. Descriptive data analysis of categorical variables is presented in numbers and proportions. Hypothesis testing for categorical unpaired variables is performed using the Chi-square test; if the Chi-square test requirements are not met, Fisher's exact test performs it. Descriptive data analysis of numerical variables with normal distribution is presented in the form of mean + standard deviation, analysis of numerical descriptive data with abnormal distribution in the form of the median (minimum value-maximum value).

Assessing data with normal distribution or abnormal distribution can be descriptive with variance or analytical coefficient with Shapiro-Wilk. Analysis of normally distributed data using unpaired t-test, whereas if the data are not generally distributed with MannWhitney. Statistical tests to prove the diagnostic value of fibrinogen/d-dimer ratio as a prediction of the occurrence of "slow-flow" in CHD contains several quantities such as sensitivity, specificity, possible, probable ratio, probable negative ratio, positive predictive value, and negative predictive value. Several variables were also performed multivariate analysis using logistic regression.

\section{Results}

Table 1 shows that confounding variables of age, sex, smoking history, history of diabetes mellitus, history of hypertension, history of heart disease, history of dyslipidemia, and BMI did not differ significantly between groups of patients who had CSFP and regular flow groups.

Table 1 shows that the levels of fibrinogen, d-dimer, and fibrinogen/d-dimer ratio did not show any significant difference between the CSFP group and the normal flow group, $p>0.05$. The validity test of the fibrinogen/d-dimer ratio to CSFP can be seen in Table 1. There were 10 patients $(41.7 \%)$ with a fibrinogen/d-dimer ratio $>0.9$ showing CSFP and 14 samples $(66.7 \%$ ) did not show CSFP. At a value of $\leq 0.9$, there were 14 samples (66.7\%) with CSFP and seven samples (33.3\%) without CSFP. At a cut-off point of 0.9 the fibrinogen/d-dimer ratio results in a sensitivity value of $41.7 \%$; specificity value $33.3 \%$; positive predictive value $41.7 \%$; and negative predictive value $33.3 \%$.

\section{Discussion}

Fibrinogen and its metabolites can cause endothelial dysfunction through several mechanisms. Atherosclerotic lesions contain much fibrin, either in the wall of thrombus on the surface of intact plaque or spread throughout the plaque. The phenomenon is associated with decreased fibrinolytic activity and plasminogen concentration. It has been explained that fibrin triggers cell proliferation, cell migration, and fibronectin-binding, which triggers cell migration and adhesion. Fibrinogen and its decomposition products mediate the transport of adhesion molecules at the endothelial surface and further migration to the intima tunica. Decomposition products located in the inner layer can trigger mitogenesis and collagen synthesis, attract leukocytes, and increase vascular permeability.

Furthermore, fibrin in atherosclerotic plaque has a relationship with low-density lipoprotein (LDL) and lipid accumulation, which leads to the formation of lipid nuclei from atherosclerotic lesions. Furthermore, 
Table 1: Relationships between variables with coronary slow flow phenomenon

\begin{tabular}{|c|c|c|c|c|c|c|}
\hline \multirow[t]{3}{*}{ Characteristic } & \multicolumn{6}{|c|}{ Coronary slow flow phenomenon } \\
\hline & \multicolumn{2}{|c|}{ Coronary slow flow phenomenon $(+)$} & \multicolumn{4}{|c|}{ Coronary slow flow phenomenon (-) } \\
\hline & $\mathrm{n}$ & $\%$ & $\mathrm{n}$ & $\%$ & Total & ${ }^{*} \mathrm{p}$ \\
\hline \multicolumn{7}{|l|}{ Age } \\
\hline $30-39$ & 2 & 100.0 & - & - & 2 & 0.489 \\
\hline $40-49$ & 6 & 42.9 & 8 & 57.1 & 14 & \\
\hline $50-59$ & 7 & 53.8 & 6 & 46.2 & 13 & \\
\hline$\geq 60$ & 9 & 56.3 & 7 & 43.7 & 16 & \\
\hline Total & 24 & 53.3 & 21 & 46.7 & 45 & \\
\hline \multicolumn{7}{|l|}{ Gender } \\
\hline Male & 14 & 45.2 & 17 & 54.8 & 31 & \\
\hline Female & 10 & 71.4 & 4 & 28.6 & 14 & 0.102 \\
\hline Total & 24 & 53.3 & 21 & 46.7 & 45 & \\
\hline \multicolumn{7}{|l|}{ Smoking } \\
\hline Yes & 5 & 50.0 & 5 & 50.0 & 10 & 0.811 \\
\hline No & 19 & 54.5 & 16 & 45.7 & 35 & \\
\hline Total & 24 & 53.3 & 21 & 46.7 & 45 & \\
\hline \multicolumn{7}{|l|}{ Diabetes mellitus } \\
\hline Yes & 3 & 50.0 & 3 & 50.0 & 6 & 0.810 \\
\hline No & 21 & 53.8 & 18 & 46.2 & 39 & \\
\hline Total & 24 & 53.3 & 21 & 46.7 & 45 & \\
\hline \multicolumn{7}{|l|}{ Hypertension } \\
\hline Yes & 13 & 52.0 & 12 & 48,0 & 25 & 0.841 \\
\hline No & 11 & 55.0 & 9 & 45.0 & 20 & \\
\hline Total & 24 & 53.3 & 21 & 46.7 & 45 & \\
\hline \multicolumn{7}{|l|}{ Dyslipidemia } \\
\hline Yes & 4 & 66.7 & 2 & 33.3 & 6 & 0.482 \\
\hline No & 20 & 51.3 & 19 & 48.7 & 39 & \\
\hline Total & 24 & 53.3 & 21 & 46.7 & 45 & \\
\hline \multicolumn{7}{|l|}{ Heart disease } \\
\hline Yes & 5 & 62.5 & 3 & 37.5 & 8 & 0.567 \\
\hline No & 19 & 51.4 & 18 & 48.6 & 37 & \\
\hline Total & 24 & 53.3 & 21 & 46.7 & 45 & \\
\hline \multicolumn{7}{|l|}{ Body mass index } \\
\hline Normolweight & 12 & 50.0 & 12 & 50.0 & 24 & 0.478 \\
\hline Overweight & 11 & 55.0 & 9 & 45.0 & 20 & \\
\hline Underweight & 1 & 100.0 & 0 & 0.0 & 1 & \\
\hline Total & 24 & 53.3 & 21 & 46.7 & 45 & \\
\hline \multicolumn{7}{|l|}{ Fibrinogen } \\
\hline High & 2 & 40.0 & 3 & 60.0 & 5 & 0.526 \\
\hline Normal & 22 & 55,0 & 18 & 45.0 & 40 & \\
\hline Total & 24 & 53.3 & 21 & 46.7 & 45 & \\
\hline \multicolumn{7}{|l|}{ d-Dimer } \\
\hline High & 10 & 55.6 & 8 & 44.4 & 18 & 0.807 \\
\hline Normal & 14 & 51.9 & 13 & 48.1 & 27 & \\
\hline Total & 24 & 53.3 & 21 & 46.7 & 45 & \\
\hline \multicolumn{7}{|c|}{ Fibrinogen/d-dimer ratio } \\
\hline$>0.9$ & 10 & $41.7 \%$ & 14 & $66.7 \%$ & 24 & 0.094 \\
\hline$\leq 0.9$ & 14 & $66.7 \%$ & 7 & $33.3 \%$ & 21 & \\
\hline Total & 24 & 53.3 & 21 & 46.7 & 45 & \\
\hline
\end{tabular}

pro-inflammatory cytokines, such as interleukin 6 (IL-6) and tumor necrosis factor-alpha, are produced by blood vessels, adipose tissue, and myocardium; this increases the synthesis of nitric oxide and leukocyte migration into the subendothelial space. These cytokines also have a regulatory role, stimulating the liver for the synthesis of acute-phase proteins, such as fibrinogen, and as a result of inflammatory and prothrombotic reactions. Thus, fibrinogen plays a role in the formation of atherosclerotic plaque in the early stages of CHD [9], [10], [11], [12], [13], [14], [15].

Atherosclerotic lesions initially arise at predilection sites where endothelial cell morphology changes due to changes in hemodynamic pressure (shear stress and turbulence of blood flow in arterial branches) and increased levels of lipids and inflammatory factors. Shear stress is directly proportional to the viscosity of blood flow, where fibrinogen plays a role. With an increase in fibrinogen levels contribute to increased hemodynamic pressure of blood vessel walls. As a result, endothelial cells secrete various adhesion molecules (intercellular adhesion molecules-1 [ICAM-1] and vascular cell adhesion molecule-1), chemotactic factors (MCP-1), and growth factors and loss of anticoagulant function due to increased thrombogenicity [10], [11]. Fibrinogen binds to endothelial cells through ICAM- 1 and settles in the subendothelial layer of the extracellular matrix at specific concentrations. In the subendothelial layer of the extracellular matrix, fibrinogen increases shear stress, which induces nuclear activation factor $\mathrm{\kappa B}$ (NF-kB), which increases the response of endothelial cells to disrupt blood flow. Based in vitro studies show that fibrinogen induces MCP-1 and IL-8 expression in endothelial cells through NF-kB activation. MCP-1 has a role in the process of atherogenesis in the recruitment of monocytes to the cell wall [12], [13].

Other endothelial cells also express tissue factors, which cause conversion of fibrinogen to fibrin in cell walls. Fibrinogen stimulates endothelial cells to secrete von-Willebrand factor proliferation. Increased endothelial cell permeability causes LDL particles to spread into the subendothelial cavity. Fibrinogen also contributes to the sequestration of $\mathrm{LDL}$ and lipoprotein $\mathrm{A}$ particles, which are atherogenic molecules. The tendency of lipoprotein A to accumulate in artery walls depends on its binding to fibrin. Oxidized LDL stimulates endothelial cells to stimulate adhesion molecules, chemotaxis, and growth factors. Molecular interactions between fibrinogen and $\alpha \mathrm{M} \beta 2$ integrin receptors facilitate the accumulation of 
monocytes in cell walls and differentiate into macrophages that express toll-like receptors and scavengers receptors. Fibrinogen stimulates macrophages to re-produce chemokines such as MCP-1 and may play a role in the exacerbation of inflammation in cell walls. Oxidized LDL also increases thrombogenicity of the lesion by stimulating TF production in endothelial cells and smooth muscle [16], [17], [18], [19], [20], [21], [22]. The process of arterial thrombosis is associated with the incidence of acute myocardial infarction. Several risk factors for arterial thrombosis strengthen endothelium injury [23], [24], [25], [26]. Endothelium in normal circumstances, bridging blood vessel wall interactions and plays a central role in preventing intraluminal thrombus formation [24]. Damage to endothelium can alter the above functions and is a predisposition to inflammation, thrombosis, vasoconstriction, and vascular muscle growth [23], [24]. A ruptured plaque will be covered by a thrombus and is a significant cause of the incidence of an acute myocardial ischemic syndrome. The results of the post mortem examination showed that plaque that ruptures more often results in thrombus than endothelial erosion. The response to plaque damage involves introducing blood from the lumen into the lipid nucleus so that there is an intraplaque thrombus [24]. However, this study has limitations because it was used a minimal number of samples.

This study showed that there was no difference in levels of fibrinogen and D-dimer in groups with CSFP and normal flow. This shows that fibrinogen and D-dimer do not play a significant role in the CSFP process. CSFP is indeed still a mystery and a challenge for researchers to uncover the pathophysiological reasons for this disorder. The various etiological roles of this possible disorder still need further exploration and detail, ranging from the role of the renin-angiotensinaldosterone system, the role of the autonomic nervous system, to the role of other endothelial factors.

\section{Conclusion}

This study proves that fibrinogen has specific but not sensitive predictors of SCFP. The d-dimer value is also not accurate as a CSFP predictor. This study proves that the fibrinogen/D-dimer ratio is not accurate as a predictor of CSFP events.

\section{Acknowledgment}

The authors would express their sincere gratitude to the Medical Research Unit of the Faculty of Medicine, Universitas Sriwijaya, Palembang, Indonesia.

\section{References}

1. Bauer T, Zeymer U, Diallo A, Vicaut E, Bolognese L, Cequier A, et al. Impact of preprocedural TIMI flow on clinical outcome in low-risk patients with ST-elevation myocardial infarction: Results from the Atlantic study. Catheter Cardiovasc Interv. 2020;95(3):494-500. https://doi.org/10.1002/ccd.28318 PMid:31067010

2. Fineschi M, Bravi A, Gori T. The slow coronary flow phenomenon: Evidence of preserved coronary flow reserve despite increased resting microvascular resistances. Int J Cardiol. 2008;127(3):35861. https://doi.org/10.1016/j.ijcard.2007.06.010

PMid: 17651842

3. Beltrame JF, Limaye SB, Horowitz JD. The coronary slow flow phenomenon-a new coronary microvascular disorder. Cardiology. 2002;97(4):197-202. https://doi.org/10.1159/000063121 PMid: 12145474

4. Sezgin AT, Sigirci A, Barutcu I, Topal E, Sezgin N, Ozdemir R, et al. Vascular endothelial function in patients with slow coronary flow. Coron Artery Dis. 2003;14(2):155-61. https://doi. org/10.1097/00019501-200304000-00008 PMid: 12655279

5. Tripodi A. D-dimer testing in laboratory practice. Clin Chem. 2011;57(9):1256-62.

PMid:21719689

6. Hochuli M, Duewell S, Frauchiger B. Quantitative d-dimer levels and the extent of venous thromboembolism in CT angiography and lower limb ultrasonography. Vasa. 2007;36(4):267-74. https://doi.org/10.1024/0301-1526.36.4.267

PMid: 18357919

7. Li JJ, Zheng X, Li J. Statins may be beneficial for patients with slow coronary flow syndrome due to its anti-inflamatory property. Med Hypotheses. 2007;69(2):333-7. https://doi.org/10.1016/j. mehy.2006.09.070

PMid: 17215087

8. Simsel H, Sahin M, Gunes $Y$, Akdag S, Akil MA. A nove echocardiographic method as an indicator of endothelial dysfunction in patients with coronary slow flow. Eur Rev Med Pharmacol Sci. 2013;17(5):689-93.

PMid:23543453

9. Mangieri E, Macchiarelli G, Ciavolella M. Slow coronary flow: Clinical and histopathological features in patients with otherwise normal epicardial coronary arteries. Cathet Cardiovasc Diagn. 1996;37(4):375-81. https://doi.org/10.1002/ (sici)1097-0304(199604)37:4<375::aid-ccd7>3.0.co;2-8 PMid:8721694

10. Seyyed-Mohammadzad MH, Rashtchizadeh S, Khademvatani K, Afsargharehbagh R, Nasiri A, Sepehrvand N. Ventricular dysfunction in patients with coronary slow-flow phenomenon: A single-center case-control study. Heart Views. 2020;21(2):60-4. https://doi.org/10.4103/heartviews.heartviews_119_18 PMid:33014297

11. Wang Y, Ma C, Zhang Y, Guan Z, Liu S, Li Y, et al. Assessment of left and right ventricular diastolic and systolic functions using two-dimensional speckle-tracking echocardiography in patients with coronary slow-flow phenomenon. PLoS One. 2015;10(2):e0117979. https://doi.org/10.1371/journal. pone. 0117979

PMid:25706989

12. Gulel O, Akcay M, Soylu K, Aksan G, Yuksel S, Zengin H, et al. Left ventricular myocardial deformation parameters are affected by coronary slow flow phenomenon: A study of speckle tracking echocardiography. Echocardiography. 2016;33(5):714-23. https://doi.org/10.1111/echo.13146 


\section{PMid:26668075}

13. Demirkol MO, Yaymaci B, Mutlu B. Dipyridamole myocardial perfusion single photon emission computed tomography in patients with slow coronary flow. Coron Artery Dis. 2002;13:2239. https://doi.org/10.1097/00019501-200206000-00004 PMid:12193849

14. TIMI Study Group. The thrombolysis in myocardial infarction (TIMI) trial. Phase I findings. N Engl J Med. 1985;312(14):9326. https://doi.org/10.1056/nejm198504043121437 PMid:4038784

15. Stone GW. PAMI (primary angioplasty in myocardial infarction) stent pilot trial. Clin Cardiol. 1998;21(2):130. https://doi. org/10.1002/clc.4960210216 PMid:9491956

16. Sanati H, Kiani R, Shakerian F, Firouzi A, Zahedmehr A, Peighambari M, et al. Coronary slow flow phenomenon: Clinical findings and predictors. Res Cardiovasc Med. 2016;5(1):e30296. https://doi.org/10.4103/2251-9572.218699

PMid:26889458

17. Chaudhry MA, Smith M, Hanna EB, Laazzara R. Diverse spectrum of presentation of coronary slow flow phenomenon: A concise review of the literature. Cardiol Res Pract. 2012;2012:383181.

PMid:22645695

18. Singh S, Kothari SS, Bahl VK. Coronary slow flow phenomenon: An angiographic curiosity. Indian Heart J. 2004;56(6):613-7.

PMid: 15751515

19. Duncker DJ, Bache RJ. Regulation of coronary blood flow during exercise. Physiol Rev. 2008;88(3):1009-86. https://doi. org/10.1152/physrev.00045.2006

PMid:18626066
20. Hawkins BM, Savrakis S, Rousan TA, Abu-Fadel M, Schecter E. Coronary slow flow prevalence and clinical correlations. Circ J. 2012;76(4):936-42. https://doi.org/10.1253/circj.cj-11-0959 PMid:22293446

21. Yilmaz H, Demir I, Uyar Z. Clinical and coronary angiographic characteristics of patients with coronary slow flow. Acta Cardiol. 2008;63(5):579-84. https://doi.org/10.2143/ac.63.5.2033224 PMid: 19014000

22. Arbel $\mathrm{Y}$, Rind E, Banai S, Halkin A, Berliner S, Herz I, et al Prevalence and predictors of slow flow in angiographically normal coronary arteries. Clin Hemorheol Microcirc. 2012;52(1):5-14. https://doi.org/10.3233/ch-2012-1538 PMid:22387483

23. Alvarez C, Siu H. Coronary slow flow phenomenon as an underrecognized and treatable source of chest pain: case series and literature review. J Investig Med High Impact Case Rep. 2018;6:2324709618789194. https://doi. org/10.1177/2324709618789194

24. Wang Y, Li Y, Liu S, Mu L, Li G, Yu H, et al. Value of exercise stress electrocardiography for stratification of exercise capacity and left ventricular systolic and diastolic function on coronary slow flow: Case-control study. BMC Cardiovasc Disord. 2019;19(1):288. https://doi.org/10.1186/s12872-019-01291-5 PMid:31830922

25. Gibson CM, Ryan KA, Kelley M. Methodologic drift in the assessment of TIMI grade 3 flow and its implications with respect to the reporting of angiographic trial results. The TIMI Study Group. Am Heart J. 1999; 137:1179-84. https://dx.doi. org/10.1016/s0002-8703(99)70380-7

26. Gibson CM, Cannon CP, Daley WL. TIMI frame count a quantitative method of assessing coronary artery flow. Circulation. 1996; 93:879-88. https://dx.doi.org/10.1161/01. cir.93.5.879 